\title{
On the Regional Differences in Agricultural Water Use Efficiency in China and Their Convergence
}

\author{
Xiaoyuan Geng \\ College of Economics \& Management, Heilongjiang Bayi Agricultural University, Daqing 163319, China
}

Corresponding Author Email: gengxiaoyuan0459@163.com

https://doi.org/10.18280/ijdne.150208

Received: 10 October 2019

Accepted: 25 January 2020

\section{Keywords:}

agricultural water use efficiency, regional difference, convergence, SBM model

\begin{abstract}
Lack of agricultural water resources and water pollution have become the two big challenges restricting the development of agriculture in China, so finding the ways to efficiently use agricultural water resources is of great significance. In view of this, based on the agricultural panel data of 30 provinces in China during the period from 2011 to 2017, this paper uses the SBM model which contains undesired output to evaluate the agricultural water use efficiency of each province, and applies the absolute $\beta$ convergence method and conditional $\beta$ convergence method to empirically examine the convergence characteristics of the provincial agricultural water use efficiency. According to the results, there are provincial differences in agricultural water use efficiency in China. Among all the provinces and municipalities, Beijing, Inner Mongolia, Liaoning, Shanghai, Jiangsu, Zhejiang, Shandong, Hainan, Chongqing, Yunnan, Shaanxi, Qinghai and Xinjiang achieved the optimal agricultural water use efficiency, while Hunan, Hubei, Heilongjiang, Jiangxi, Anhui and Shanxi did not perform well in terms of agricultural water use efficiency. The three major regions of China, namely East China, Central China and West China, showed very different trends - the agricultural water use efficiency was the highest in East China, followed by that in West China, and it was the lowest in Central China. Therefore, Central China is the key region where more efforts should be made in agricultural water conservation. The provincial agricultural water use efficiency exhibited absolute $\beta$ convergence and conditional $\beta$ convergence, showing a trend of lowefficiency provinces catching up with high-efficiency ones. In terms of the factors affecting agricultural water use efficiency, economic development level and agricultural water use intensity have significant negative impacts on agricultural water use efficiency, while crop planting structure significantly improves agricultural water use efficiency, and agricultural water conservancy construction and government financial support do not exert significant impacts.
\end{abstract}

\section{INTRODUCTION}

Water resources play an important role in social and economic development. It is not only a key element of production, but also an important foundation for ecology. However, the shortage of water resources has seriously affected China's sustainable development. According to statistics, China's per capita water resources is only $2,100 \mathrm{~m}^{2}$, which is less than one third of the world's average, making China one of the 13 countries in the world who are in serious shortage of water. Agriculture is the largest water-consuming sector in the national economy. By the end of 2016, agriculture had consumed 376.80 billion $\mathrm{m}^{3}$ of water resources, accounting for $62.38 \%$ of the total water consumption in China; however, the water resources per mu of cultivated land is only $70 \%$ of the world's average, and agriculture, as the primary industry, only contributed $4.35 \%$ of the GDP growth in China [1]. At the same time, wastewater pollution from agricultural production is getting more and more serious, and has become one of the major sources of pollution in China. The data shows that in 2016, in the functional areas of some important rivers and lakes in China, the overall water quality qualification rate was $73.43 \%$, and that among the areas of all national economic sectors, the agricultural areas had the lowest water quality qualification rate - only $54.6 \%$. In addition, the geographical distribution of agricultural water resources in China is highly unbalanced. There are more water resources in the south and the east and fewer in the north and the west. The uneven regional distribution has led to severe overload of agricultural water resources in some regions. The prominent contradictions between the supply and demand of agricultural water resources, the inefficient use of water and the increasingly serious water pollution have become the key problems restricting the use of agricultural water resources in China, and solving these problems will be of great significance for promoting the sustainable agricultural development. So, how is the agricultural water use efficiency in various regions of China? Are there any significant regional differences? And is there any clear convergence trend in the agricultural water use efficiency in different regions over time? The answers to these questions will not only provide strong support for the efficient use of agricultural water resources, but also serve as an important basis for promoting sustainable agricultural development in China.

At present, water resource use efficiency is a hotspot of academic research. The existing literatures on this topic 
mainly focus on the following four aspects. The first is the evaluation indices of agricultural water use efficiency, which involve single factor indices and total factor indices. The former include water consumption per 10,000 yuan of GDP, agricultural irrigation water production efficiency and average water consumption for agricultural irrigation per mu [2, 3]; the total factor indices incorporate not only water resources, but also other relevant indices such as capital and labour into the evaluation framework, that is, all elements are taken into account [4]. The single-factor index is easy to measure and operate, but it ignores the substitution effect of other factor inputs against water resources, and thus it has great limitations. On the other hand, the total factor index is more comprehensive and reasonable because it contains multiple indices. The second is the evaluation method for water resources use efficiency. There are also two main kinds of evaluation methods. One is the data envelopment analysis method (DEA). Andre et al. [5] and Sun et al. [6] constructed panel data and used the DEA method to measure the agricultural water use efficiency of Spain and China. Another method is the stochastic frontier method (SFA). For example, Battese and Coelli [7] and Kaneko et al. [8] constructed a random frontier production function, and based on this, applied the SFA method to evaluate agricultural water use efficiency. SFA needs to establish a production function when evaluating efficiency, so it can only deal with the situation with multiple inputs and a single output. DEA, however, can effectively deal with multiple inputs and outputs, which is more flexible for evaluation on the water use efficiency. The third is the regional differences in water use efficiency. Scholars such as Fang et al. discussed the regional differences in agricultural water use efficiency in China. The fourth is the influencing factors to agricultural water use efficiency $[9,10]$. Existing studies have shown that natural resources endowment [11], agricultural production conditions [12], crop planting structure [13] and government system [14], etc. are all important factors affecting agricultural water use efficiency.

Although there are already a number of studies on water resource use efficiency both at home and abroad, there are still two deficiencies. On the one hand, in terms of the establishment method for the agricultural water use efficiency evaluation model, there are few literatures that incorporate water pollution into the evaluation model as an index, so the resulting outputs have certain deviations. Nanere et al. [15] believe that ignoring the environmental factor will bring biased results of productivity measurement. On the other hand, few literatures have explored the convergence of water resources use efficiency. For example, will the regional differences in agricultural water use efficiency in China become smaller or larger over time? The answer to this question is of great significance to the sustainable use of agricultural water resources. In view of this, under the framework of data envelopment analysis, this paper incorporates the pollution produced by agricultural wastewater into the evaluation index system for agricultural water use efficiency, and applies the non-radial and non-angle SBM model to measure the agricultural water use efficiency of different regions. Based on the analysis of regional differences, this paper builds a convergence model to empirically investigate the convergence problem of agricultural water use efficiency. This study can serve as some reference to help effectively improve agricultural water use efficiency and achieve sustainable agricultural development.

\section{MATERIALS AND METHODS}

\subsection{Non-radial and non-angle SBM model}

DEA, short for data envelopment analysis, is one of the important tools to evaluate input-output efficiency. The theoretical basis for the model is Pareto Optimality in welfare economics. Suppose there is a production set, and the linear programming method is used to select the optimal production point from it. The envelope surface composed of these optimal production points will be the efficient production frontier. The decision-making units (DMUs) on the efficient production frontier are the optimal ones, that is, their efficiency value is 1 ; and conversely, those DMUs not on the efficient production frontier are non-optimal and have room for improvement. This principle shows that the efficiency measured by the DEA model is a relative term. Since the DEA model can deal with multiple inputs and outputs without having to set the production function or non-dimensionalizing the input and output variables, it is often used by both domestic and foreign scholars to evaluate input-output efficiency. However, traditional DEA models like $\mathrm{CCR}$ and $\mathrm{BCC}$ still have certain limitations in efficiency evaluation. For example, the evaluated objects have to be homogeneous, and it cannot contain any undesired output variable and cannot deal with the relaxation phenomenon of input and output [16]. To solve these shortcomings of the traditional DEA models, Tone proposed a non-radial and non-angle SBM model in 2001. Compared with those traditional models like CCR and BCC, this model is superior because it not only considers the relaxation of input and output, but also incorporates the undesired output into the evaluation system [17].

Suppose there is a production system containing undesired output variables, which is composed of $\mathrm{n}$ decision-making units (DMUs). Each DMU requires the input of m production factors and gives desired outputs $s 1$ and $s 2$ and undesired output. Let the final DMU be expressed as $D M U_{0}=$ $\left(x_{0}, y_{0}^{g}, y_{0}^{b}\right)$, where $X=\left(x_{1}, x_{2}, \ldots, x_{n}\right) \in R_{+}^{m \times n}$ is the input of factors, $Y^{g}=\left(y_{1}^{g}, y_{2}^{g}, \ldots, y_{n}^{g}\right) \in R_{+}^{s_{1} \times n}$ means the desired output, and $Y^{b}=\left(y_{1}^{b}, y_{2}^{b}, \ldots, y_{n}^{b}\right) \in R_{+}^{s_{2} \times n}$ means the undesired output. After the input and output variables are set, the SBM model containing undesired output variables can be expressed as follows:

$$
\begin{gathered}
P^{t}(x)=\left\{\left(x_{0}, y_{0}^{g}, y_{0}^{b}\right) \mid x \geq X \lambda,\right. \\
\left.y_{0}^{g} \geq y_{0}^{g} \lambda, y_{0}^{b}=y_{0}^{b} \lambda, \sum_{i=1}^{n=1} \lambda=1, \lambda \geq 0\right\}
\end{gathered}
$$

The above equation shows that the model has basic features such as convexity and boundedness. At the same time, the model is also featured with strong disposability of input and output variables and zero integration of desired output and undesired output. $\lambda$ is a positive value, referring to the weight of the entire cross section. The whole operation process of SBM is as follows:

$$
\begin{gathered}
\min \rho=\frac{1-\frac{i}{m} \sum_{i=1}^{m} \frac{s_{i}^{x-}}{x_{i o}}}{1+\frac{i}{s_{d}+s_{u}}\left(\sum_{d=1}^{d} \frac{s_{d}^{y+}}{y_{d o}}+\sum_{u=1}^{u} \frac{s_{u}^{b-}}{b_{u o}}\right)} \\
\text { s.t. } x_{0}=\sum_{j=1}^{n} \lambda_{j} x_{i j}+s_{i}^{x-}, i=1,2, \ldots, m \\
y_{0}=\sum_{j=1}^{n} \lambda_{j} y_{d j}-s_{d}^{y+}, d=1,2, \ldots, d
\end{gathered}
$$




$$
\begin{gathered}
b_{0}=\sum_{j=1}^{n} \lambda_{j} b_{u j}+s_{u}^{b-}, u=1,2, \ldots, u \\
\lambda \geq 0, s_{i}^{x-} \geq 0, s_{d}^{y+} \geq 0, s_{u}^{b-} \geq 0
\end{gathered}
$$

In Eq. (2), $s^{x-} \in R^{m}, s^{y+} \in R^{d}, s^{b-} \in R^{u}$ represent the relaxation terms of input variables, desired output variables and undesired output variables, respectively. When the relaxation terms $s^{x-}=0, s^{y+}=0$ and $s^{b-}=0$, it means that the efficiency value of the entire model $\rho=1$, that is, the efficiency reaches the optimal level. If $\rho<1$, it means inefficiency, that is, there are problems like too many input variables, insufficient desired output variables or too many undesired output variables. Only by reducing the relaxation terms of the input and output variables, can we turn inefficiency to efficiency.

\subsection{Evaluation index system}

By the research results of $\mathrm{Hu}$ and Wang [4], based on the "total factor" framework, the agricultural water uses efficiency (AWUE) studied in this paper is defined as the ratio between the target agricultural water input (TAWI) and the actual agricultural water input (AAWI). Compared with the traditional agricultural water use efficiency index, this evaluation index takes agricultural water resources and other agricultural input factors all into account, which can more accurately characterize agricultural water use efficiency. According to this definition, agricultural water use efficiency can be expressed by the following equation:

$$
A W U E=\frac{T A W I}{A A W I}=\frac{A A W I-E A W I}{A A W I}
$$

In Eq. (3), $A W U E$ represents agricultural water use efficiency, $A A W I$ is the actual agricultural water input, $E A W I$ is the excessive agricultural water input, and $T A W I$ represents the target agricultural water input, and there is $T A W I=A A W I$ EAWI.

Since the DEA method used in this paper is to measure the agricultural water use efficiency under the "total factor" framework, it is necessary to construct an evaluation index system that contains input and output variables [18]. According to the principle of scientificity, reasonability and operability, this paper constructs an input and output evaluation index system for agricultural water use efficiency. The input indices of the index system include: (1) agricultural water consumption: as an essential element of agricultural production, agricultural water not only includes the water required for irrigation and crop growth, but also the water loss incurred during agricultural irrigation; (2) agricultural land investment: land is the important carrier for crops and a basic input factor for agricultural production, and in this paper, the crop sown area is used to represent agricultural land; (3) agricultural labour: labour, as the users of agricultural water resources, is a basic element of agricultural production activities, and in this paper, agricultural workers are taken as the agricultural labour; (4) agricultural capital investment: capital investment is fundamental in the process of agricultural production, as purchase of chemical fertilizers and agricultural machinery and implementation of water conservancy construction, etc. all require capital, and since there are no agricultural capital data directly available from relevant statistical yearbooks, agricultural fixed assets investment is used in this paper to represent capital investment; (5) agricultural chemical fertilizer input: agricultural production needs to be supported by fertile land, and the fertility of the land is directly determined by agricultural chemical fertilizer, so agricultural fertilizer consumption is used in this paper as chemical fertilizer input in the evaluation system; and (6) agricultural machinery input: agricultural machinery is an important source of power in the agricultural production process, and the level of agricultural machinery directly determines the efficiency of agricultural production, so in this paper, agricultural machinery power is used to represent agricultural machinery input. There are two output indices in the evaluation index system for agricultural water use efficiency, namely desired output and undesired output. The desired output is represented by the total output value of agriculture, forestry, animal husbandry and fishery; and the undesired output is the water pollution generated during the agricultural production process, and in this paper, agricultural ammonia nitrogen emission is used to represent the undesired output. The specific meaning of each input or output index is

\begin{tabular}{|c|c|c|}
\hline Index classification & Specific index & Meaning \\
\hline \multirow{6}{*}{ Input index } & $\begin{array}{l}\text { Agricultural water } \\
\text { consumption }\end{array}$ & $\begin{array}{l}\text { Agricultural water consumption, expressed by the total consumption of agricultural water } \\
\text { resources in each province }\end{array}$ \\
\hline & Crop sown area & $\begin{array}{l}\text { Agricultural land investment, expressed by the total crop sown area in each province each } \\
\text { year }\end{array}$ \\
\hline & Agricultural workers & $\begin{array}{c}\text { Agricultural labour input, expressed by the number of agricultural workers in each } \\
\text { province by the end of each year }\end{array}$ \\
\hline & $\begin{array}{l}\text { Agricultural fixed } \\
\text { assets investment }\end{array}$ & $\begin{array}{l}\text { Agricultural capital investment, expressed by the amount of agricultural fixed assets } \\
\text { investment each year, which is also deflated with } 2011 \text { as the base period to eliminate the } \\
\text { effect of inflation }\end{array}$ \\
\hline & $\begin{array}{l}\text { Agricultural fertilizer } \\
\text { consumption }\end{array}$ & $\begin{array}{l}\text { Agricultural fertilizer input, expressed by the total fertilizer consumption in each province } \\
\text { in each previous year }\end{array}$ \\
\hline & $\begin{array}{l}\text { Agricultural } \\
\text { machinery power }\end{array}$ & $\begin{array}{c}\text { Agricultural machinery input, expressed by the total agricultural machinery power in each } \\
\text { province. }\end{array}$ \\
\hline \multirow[t]{2}{*}{ Output index } & $\begin{array}{l}\text { Total output value of } \\
\text { agriculture, forestry, } \\
\text { husbandry and fishery }\end{array}$ & $\begin{array}{l}\text { Total output of agriculture, forestry, husbandry and fishery in each province each year. } \\
\text { Similarly, to eliminate the effect of price factor, the nominal total output of agriculture, } \\
\text { forestry, husbandry and fishery is converted to the actual total output with } 2011 \text { as the } \\
\text { base period. }\end{array}$ \\
\hline & $\begin{array}{l}\text { Agricultural ammonia } \\
\text { nitrogen emission }\end{array}$ & Ammonia nitrogen emission from the agricultural wastewater in each province each year \\
\hline
\end{tabular}
listed in the Table 1.

Table 1. Evaluation index system for agricultural water use efficiency 


\subsection{Convergence model}

In the analysis framework of neoclassical economics, the convergence model was originally used to study whether there is convergence or divergence in the income levels of different countries or regions. In recent years, as people's awareness of environmental protection is gradually increasing, the application scope of the convergence model has been further expanded, from income to resources, environment and energy consumption. In this paper, conducting convergence analysis helps examine the characteristics of convergence or divergence of agricultural water use efficiency between different provinces, that is, whether the provincial differences in agricultural water use efficiency are gradually expanding or shrinking.

\subsubsection{Absolute $\beta$ convergence model}

The $\beta$ convergence model is one of the classic convergence models. It can be further divided into the absolute $\beta$ convergence model and the conditional $\beta$ convergence model. In the absolute $\beta$ convergence model, without other external control variables taken into account, the agricultural water use efficiency in different provinces will converge to the same level over time. The specific absolute $\beta$ convergence model is as follows:

$$
g A W U E_{i, t}=\alpha_{i}+\beta \operatorname{Ln}\left(A W U E_{i, t-1}\right)+\mu_{i, t}
$$

In Eq. (4), $g A W U E_{i, t}$ represents the growth rate of agricultural water use efficiency in the $i$-th province in the $t$-th year, and its calculation process is $g A W U E_{i, t}=\Delta L n\left(A W U E_{i, t}\right)=\operatorname{Ln}\left(A W U E_{i, t}\right)-\operatorname{Ln}\left(A W U E_{i, t-1}\right)$;

$\operatorname{Ln}\left(A W U E_{i, t-1}\right)$ represents the natural logarithm of the agricultural water use efficiency in the $i$-th province in the $(t$ 1)-th year; if the coefficient of $\beta$ is negative and passes the significance level test, it indicates that agricultural water use efficiency has the obvious feature of absolute $\beta$ convergence; $\mu_{i, t}$ is the random error term.

\subsubsection{Conditional $\beta$ convergence model}

When the above-mentioned absolute $\beta$ convergence model is used to investigate agricultural water use efficiency, the premise is that the initial level of efficiency is used as the decisive variable. However, in reality, there are many nonnegligible factors that affect agricultural water use efficiency, thereby affecting the convergence of agricultural water use efficiency, which is manifested as conditional $\beta$ convergence. By the research results of Tong et al. [19] and $\mathrm{Li}$ and $\mathrm{Xu}$ [20], this paper summarizes the factors that affect agricultural water use efficiency into five major factors, namely economic development level, agricultural water intensity, farmland water conservancy construction, crop planting structure and government financial support. While selecting variables for the five influencing factors, this paper also describes their mechanisms of impact on agricultural water use efficiency.

Economic development level $(G D P)$ : the economic development level directly determines the income level of peasants, which further affect peasants' sensitivity to the price of agricultural water. In this paper, GDP per capita is used to represent the level of regional economic development.

Agricultural water uses intensity (WUI): the intensity of agricultural water use is the intensity of water consumption for agricultural production in a region, which reflects the development level of agricultural water conservation technologies in the region. Agricultural water conservation technologies are related to the choice of agricultural irrigation methods, which will also have an important impact on the use of agricultural water resources. In this paper, the proportion of agricultural water consumption in total water consumption is used to represent agricultural water use intensity.

Agricultural water conservancy construction (WCC): agricultural water conservancy construction is carried out to solve the uneven distribution in China both in time and space and exert the functions of water storage and transfer in different regions and at different time. This apparently plays an important role in the rational use of agricultural water resources. In this paper, the regional reservoir capacity is used to reflect the level of agricultural water conservancy construction.

Crop planting structure (APS). The crops grown in China are mainly grain crops and cash crops. Among them, rice and wheat are traditional food crops. During the planting process, certain water resources are consumed, which in turn affects the entire agricultural water demand. This obviously affects agricultural water use efficiency. In this paper, the proportion of grain sown area in the crop sown area is used to represent the crop planting structure.

Government financial support (GOV): the government's financial support for agricultural development reflects the importance the government attaches to agriculture. Great financial support from the government not only facilitates agricultural water conservancy technologies in a region, but also helps improve agricultural water use efficiency. In this paper, the financial support in agricultural, forestry and water affairs are used to represent government financial support.

Then, this paper incorporates the above five influencing factors to the convergence model to obtain the conditional $\beta$ convergence model for agricultural water use efficiency. The basic form of the model is as follows:

$$
\begin{aligned}
g A W U E_{i, t}= & \alpha_{i}+\beta_{1} \operatorname{Ln}\left(A W U E_{i, t-1}\right) \\
& +\beta_{2} X_{i, t}+\mu_{i, t}
\end{aligned}
$$

In Eq. (5), the meanings of $g A W U E_{i, t}$ and $\operatorname{Ln}\left(A W U E_{i, t-1}\right)$ are the same as in the absolute $\beta$ convergence model. $X_{i, t}$ represents the set of control variables selected in this paper, including economic development level $\left(G D P_{i, t}\right)$, expressed by the natural logarithm of GDP per capita of each province; agricultural water intensity $\left(W U I_{i, t}\right)$, expressed by the proportion of agricultural water consumption in total water consumption in each province; agricultural water conservancy construction $\left(W C C_{i, t}\right)$, expressed by the natural logarithm of the reservoir capacity in each province; crop planting structure (APS), expressed by the proportion of the grain sown area in the crop sown area in each province; and government financial support $(G O V)$, expressed by the natural logarithm of the financial support for agricultural, forestry and water affairs.

\subsection{Data source}

In order to ensure the comprehensiveness and operability of the data of each variable in the model, this paper finally selects the panel data of 30 provinces in China from 2011 to 2017 as the object of research. Due to serious lack of data from Tibet, Hong Kong, Macau and Taiwan, these regions are not included in the research. Finally, the data of the variables, such as agricultural water consumption, grain sown area, crop sown area, number of agricultural workers, agricultural fixed assets 
investment, agricultural fertilizer consumption, total output value of agricultural, forestry, animal husbandry and fishery, agricultural ammonia nitrogen emission, GDP per capita, total regional water use, reservoir capacity, financial support for agriculture, forestry and water affairs, are all extracted from China Statistical Yearbook, China Population and Employment Statistics Yearbook, Water Resources Bulletin, China Rural Statistical Yearbook, China Environmental Yearbook and local statistical yearbooks.

\section{RESULTS}

\subsection{Regional differences in agricultural water use efficiency}

According to the evaluation index system for agricultural water use efficiency constructed above, this paper collected the data of the input and output variables, and then based on this, used maxDEA to obtain the agricultural water use efficiency values of 30 provinces and municipalities in China from 2011 to 2017. During the sample period, the average value of agricultural water use efficiency in each province is shown in Figure 1. It can be seen that there were great provincial differences in agricultural water use efficiency in China. Among the 30 provinces and municipalities, 13 reached the frontier of agricultural water use efficiency, namely Beijing, Inner Mongolia, Liaoning, Shanghai, Jiangsu, Zhejiang, Shandong, Hainan, Chongqing, Yunnan, Shaanxi, Qinghai and Xinjiang, accounting for $43.33 \%$ of all the provinces under investigation. The other provinces did not reach the frontier, which means they experienced agricultural water use inefficiency to varying degrees. During the sample period, Fujian and Jilin had an average agricultural water use efficiency of above 0.9; Gansu and Guizhou had an average efficiency of 0.8-0.9; Henan had an average efficiency of 0.70.8; Sichuan and Hebei had an average efficiency of 0.6-0.7; those with an average efficiency of 0.5-0.6 included Guangxi, Tianjin, Ningxia, Guangdong and Hubei; those with an average efficiency of 0.4-0.5 were Hunan and Heilongjiang; and those with an average efficiency of less than 0.4 were Jiangxi, Anhui and Shanxi. From the regional differences in agricultural water use efficiency, it can be seen that the agricultural water use efficiency of most eastern coastal provinces and municipalities reached the frontier, which can be mainly attributed to their developed economy, advanced agricultural water conservation technologies and mature management systems. Some provinces in West China also had higher agricultural water use efficiency, but due to different reasons. For example, the drought climate in provinces such as Shaanxi, Qinghai and Xinjiang forced these provinces to vigorously develop water-saving agriculture, with particular emphasis on achieving efficient agricultural irrigation; and provinces such as Chongqing and Yunnan had fewer agricultural irrigations as the natural precipitation there was sufficient to meet the water demand of agricultural production, and accordingly, the losses of water resources were lower. On the contrary, Hunan, Hubei, Heilongjiang, Jiangxi, Anhui, and Shanxi in Central China had low agricultural water use efficiency. Large water consumption for agricultural irrigation, extensive agricultural water use and limited proportion of water-saving irrigation were the main reasons.

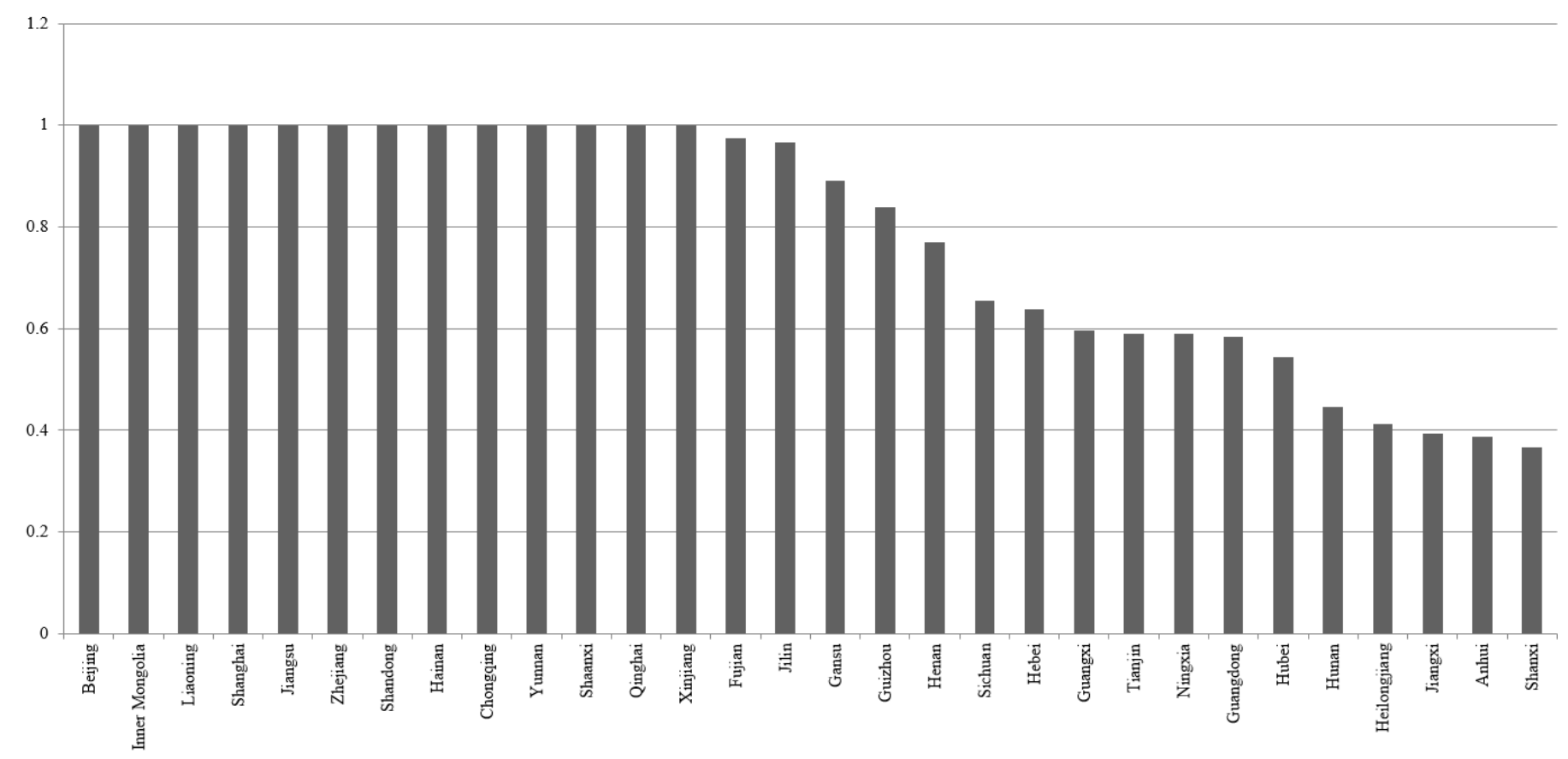

Figure 1. Agricultural water use efficiency by province in China during 2011-2017

China consists of three major regions: East China, Central China and West China. Figure 2 shows the changes in agricultural water use efficiency in the country and the three major regions during 2011-2017. According to this figure, the nationwide agricultural water use efficiency was relatively stable with little overall change during the sample period; the agricultural water use efficiency in East China was stable before 2014, and went upwards after 2014; the agricultural water use efficiency in West China changed similarly with that in East China before 2014, but it declined slowly after 2014; the efficiency in Central China showed a U-shape trend, that is, it decreased first and then rose, during the sample period. The average value of agricultural water use efficiency in East China was 0.8897 , significantly higher than the national 
average of 0.7881 ; that in West China was 0.8701 , not much different from that in East China; and that in Central China was only 0.5357 , which was not only well below the averages of East China and West China, but also lower than the national average. This reflects that, compared with East China and West China, Central China use agricultural water resources more inefficiently. If agricultural water use efficiency in Central China is increased to the production frontier, the nationwide water conservation will be significantly improved.

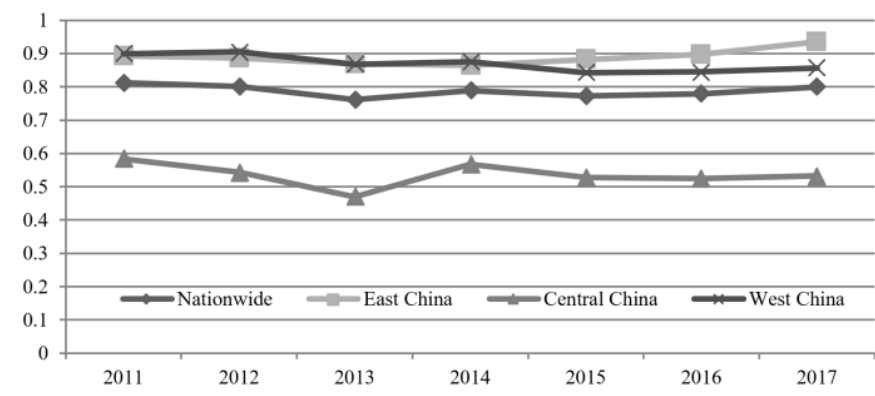

Figure 2. Changing trends of agricultural water use efficiency throughout China and in the three major regions during 2011-2017

\subsection{Convergence analysis of agricultural water use efficiency}

According to equations (4) and (5), this paper used the software Stata 12.0 to conduct empirical tests on the convergence of agricultural water use efficiency in 30 provinces and municipalities in China from 2011 to 2017. Table 2 gives the regression results of the fixed effect model and the random effect model of absolute $\beta$ convergence and conditional $\beta$ convergence, respectively. According to the regression results of the absolute $\beta$ convergence of agricultural water use efficiency, the value of Hausman test was 55.70, and passed the $1 \%$ significance level test, which indicates that there are entity fixed effects in the equation, so the regression results of the fixed effect model were used. The same is true of the conditional $\beta$ convergence regression results of agricultural water use efficiency. Compared with those of the random effect model, the results of the fixed effect model are more suitable. So whether for absolute $\beta$ convergence or conditional $\beta$ convergence, the regression results of the fixed effect model were used for analysis.

According to the results of the absolute $\beta$ convergence fixed effect model, the estimated coefficients of $\operatorname{Ln}\left(A W E_{t-1}\right)$ were all negative and passed the $1 \%$ significance level test, indicating that the agricultural water use efficiency in China has significant characteristics of absolute $\beta$ convergence. But it also reflects that the existence of absolute $\beta$ convergence is gradually narrowing down the gaps in agricultural water use efficiency between different provinces, showing that those areas with low agricultural water use efficiency are catching up with those with high efficiency.

After other influencing factors were added as control variables, $A d j R^{2}$ in the conditional $\beta$ convergence fixed effect model was 0.5019 , significantly greater than that in the absolute $\beta$ convergence fixed effect model, which means that the explanatory ability of the conditional $\beta$ convergence model was improved. After other factors were controlled, the coefficients of $\operatorname{Ln}\left(A W E_{t-1}\right)$ were also negative and passed the $1 \%$ significance level test, which shows that provincial agricultural water use efficiency also has characteristics of conditional $\beta$ convergence, and the rate of conditional convergence was significantly greater than that of the absolute convergence, because conditional convergence incorporated external factors that affect agricultural water use efficiency and took into account the heterogeneity of agricultural water resource conditions in different provinces. This accelerated the convergence rate of agricultural water use efficiency and shorten the convergence cycle, and the empirical test results of convergence were more accurate.

Table 2. Regression result of the agricultural water use efficiency convergence

\begin{tabular}{|c|c|c|c|c|}
\hline \multirow{2}{*}{ Variable } & \multicolumn{2}{|c|}{ Absolute convergence } & \multicolumn{2}{|c|}{ Conditional convergence } \\
\hline & \multicolumn{4}{|c|}{ Fixed effect Random effect Fixed effect Random effect } \\
\hline$I n\left(A W I J F_{t}\right)$ & $-0.9786 * * *$ & $-0.0593 * *$ & $-1.0337 * * *$ & $-0.0818^{* * *}$ \\
\hline $\operatorname{Ln}\left(A W \cup E_{t-1}\right)$ & $(-9.21)$ & $(1.99)$ & $(-10.44)$ & $(-2.55)$ \\
\hline$G D P$ & & & $\begin{array}{c}-0.1218^{*} \\
(-1.56)\end{array}$ & $\begin{array}{c}0.0603 * * \\
(2.48)\end{array}$ \\
\hline$W U I$ & & & $\begin{array}{c}-1.3506^{* * *} \\
(-4.53)\end{array}$ & $\begin{array}{l}0.0457 \\
(0.91)\end{array}$ \\
\hline$W C C$ & & & $\begin{array}{c}0.0268 \\
(0.90)\end{array}$ & $\begin{array}{c}0.0006 \\
(0.0085)\end{array}$ \\
\hline$A P S$ & & & $\begin{array}{c}0.9960 * * * \\
(3.85)\end{array}$ & $\begin{array}{c}0.0099 \\
(0.16)\end{array}$ \\
\hline GOV & & & $\begin{array}{l}0.0557 \\
(1.14)\end{array}$ & $\begin{array}{l}-0.0225 \\
(-1.35)\end{array}$ \\
\hline $\operatorname{Adj} R^{2}$ & 0.3628 & 0.3628 & 0.5019 & 0.1631 \\
\hline$o b s$ & 180 & 180 & 180 & 180 \\
\hline Hausman & 55.7 & $0 * * *$ & 79 . & $35 * * *$ \\
\hline
\end{tabular}

Note: the data in brackets are T-test values, and *,** and *** represent the significance level of $10 \%, 5 \%$ and $1 \%$, respectively.

In addition, judging from the results of the conditional $\beta$ convergence fixed effect model, different control variables had different effects on agricultural water use efficiency: (1) the economic development level $(G D P)$ had a negative effect on agricultural water use efficiency, and it passed the $10 \%$ significant level test, which shows that the increase in GDP per capita adversely affects agricultural water use efficiency. The possible reason is that with the increase in GDP per capita, the income level of rural residents improves, making peasants less sensitive to the price of agricultural water. Peasants are more inclined to use extensive water use methods such as flood irrigation and continuous irrigation, resulting in more natural losses in agricultural water use and reducing the agricultural water use efficiency to a certain extent. (2) The estimated coefficient of agricultural water intensity $(W U I)$ was significantly negative at the significance level of $1 \%$, which means that the higher the proportion of agricultural water use in the total water use is in the entire region, the more negative impact it will have on the improvement of agricultural water use efficiency. The possible reason is that, regions with a high proportion of agricultural water use are often traditional agricultural provinces. Not only are these regions lagging behind in economic development, but they also have not widely promoted agricultural water-saving technologies. What is more, the agricultural production there has great demand for water resources. All of these lead to serious waste of water resources. (3) The agricultural water conservancy construction (WCC) had a positive effect on agricultural water use efficiency, but it failed the significant level test. The possible reason is that although agricultural water conservancy construction has played the role of water storage, in some provinces, the increase in reservoir capacity is still limited in adjusting the water use time and space for agricultural 
production, so the estimated coefficient of agricultural water conservancy construction is not significant. (4) The estimated coefficient of crop planting structure (APS) was positive, and it passed the $1 \%$ significance level test, indicating that the higher the proportion of grain sown area is in crop sown area, the more positive effect it will have on agricultural water use efficiency. Compared with cash crops, grain crops have the advantages of long production cycle, relatively small demand for water resources and fertilizers, and high degree of production intensification. Therefore, the expansion of grain sown area has a positive effect on reducing the demand for water resources and fertilizers and improving agricultural water use efficiency. (5) Government financial support ( $G O V$ ) has a positive effect on agricultural water use efficiency, but the effect is not significant, either. The possible reasons include the irrational allocation of funds for agriculture, forestry and water affairs and the inefficient use of funds. Funds flow more to poverty alleviation and agriculture subsidy and not enough attention is paid to improving the use of agricultural water resources.

\section{DISCUSSION}

Water is the foundation of agricultural development, but the current agricultural water use in China is still facing two challenges: On the one hand, China has a large agricultural population and agricultural economy is developing rapidly, making the demand for water resources in agricultural production remain high. However, the use of agricultural water resources in most provinces in China is relatively extensive, with serious waste of water resources, and some areas are even in serious shortage of water for agriculture. On the other hand, with the continuous improvement of agricultural modernization and the wide application of chemical fertilizers and pesticides as well as agricultural machinery, water pollution caused by agricultural production is becoming more and more severe, but some local governments still fail to realize the importance of agricultural non-point source pollution control, resulting in irreversible water pollution in some areas. In view of this, to effectively solve the growing shortage of agricultural water resources and serious pollution, the Chinese government has attached great importance to the efficient use of water resources. For the purpose of water saving, it has transformed the use methods of water resources, and formulated the most stringent water management system. For example, in 2015, the State Council promulgated the Action Plan for Water Pollution Prevention and Control, which, on the one hand, requires that efforts should be made to strengthen water pollution prevention and control, and control the total amount of water consumed to prevent water shortage; and on the other hand, encourages the use of agricultural water conservation technologies, in an attempt to develop water-saving agriculture and improve irrigation efficiency. The report at the $19^{\text {th }}$ National Congress of the Communist Party of China also clearly states that water pollution prevention and control must be further accelerated to achieve comprehensive resource conservation and recycling. In order to effectively achieve the efficient use of agricultural water resources, China is currently conducting agricultural water conservation and agricultural non-point source pollution control activities. At the $31^{\text {st }}$ "China Water Week", the Chinese government clearly emphasized that the agricultural sector was a major consumer of water resources, and that the key to the success of water conservation lied in agriculture.

In view of this, this paper takes 30 provinces in China from 2011 to 2017 as the research objects, uses the DEA method to measure the agricultural water use efficiency of each province, and applies the empirical model to analyze the convergence of provincial agricultural water use efficiency. This will not only help us recognize the current regional differences in agricultural water use efficiency in China, but also allows us to see the convergence characteristics of agricultural water use efficiency between provinces. This is conducive to identifying the key regions where agricultural water use efficiency should be improved in China and digging out the key factors driving the convergence of agricultural water use efficiency, so this study can be used as a certain reference when local governments are formulating their own scientific agricultural water use policies.

\section{CONCLUSION}

Based on the constructed evaluation index system for agricultural water use efficiency, this paper uses the DEA method to measure the agricultural water use efficiency of 30 provinces and municipalities in China from 2011 to 2017. At the same time, it analyzes the regional differences in agricultural water use efficiency, builds a convergence model on this basis and empirically examines the convergence characteristics of agricultural water use efficiency. Finally, the following conclusions are drawn

First, according to the calculation results of agricultural water use efficiency, 13 provinces reached the production frontier, namely Beijing, Inner Mongolia, Liaoning, Shanghai, Jiangsu, Zhejiang, Shandong, Hainan, Chongqing, Yunnan, Shaanxi, Qinghai and Xinjiang. These provinces are mainly located in East China and West China. Other provinces did not achieve the optimal agricultural water use efficiency and have room for improvement, especially those in Central China, like Hunan, Hubei, Heilongjiang, Jiangxi, Anhui and Shanxi, who had low agricultural water use efficiency and should be regarded as the key regions in China that ought to make more efforts in agricultural conservation. The three major regions of China, namely East China, Central China and West China, showed different trends. The order of these regions in terms of average agricultural water use efficiency is East China, West China and Central China, from high to low. Compared with those of East China and West China, the level of agricultural water use efficiency in Central China is much lower. Finally, from the estimation results of the convergence model, it can be found that the agricultural water use efficiency in China has significant absolute convergence characteristics, and that the gaps in agricultural water use efficiency among provinces are gradually narrowing down over time, and that in addition, the conditional convergence rate of agricultural water use efficiency is significantly higher than the absolute convergence rate. From the estimated results of various influencing factors, economic development level, agricultural water using intensity and crop planting structure have different effects on agricultural water use efficiency, while agricultural water conservancy construction and government financial support do not exert very much significant effects.

The research conclusions of this paper will help China realize the efficient use of agricultural water resources and narrow the regional gaps in the future. The specific implications for policy making are as follows: First, there is 
still a lot of room for improvement in terms of agricultural water use efficiency in China, showing that agricultural development is still facing the dual tasks of both saving water and protecting the water environment. Second, as the agricultural water use efficiency exhibits significant regional differences, the government must fully consider the actual local conditions like local resources endowment, agricultural development level and construction of water conservancy facilities when setting agricultural water-saving goals and avoid making any one-size-fits-all policy. Third, the agricultural water use efficiency in China shows an obvious convergence trend over time, which means the regions with low agricultural water use efficiency are catching up with those with high efficiency. Therefore, what China needs to do is further accelerate this convergence trend and narrow down the gaps with leading regions more quickly so as to achieve efficient use of agricultural water resources on a nationwide level.

\section{ACKNOWLEDGEMENTS}

This paper was supported by Science Foundation of Heilongjiang Province of China (Youth Science Foundation) Performance Evaluation and Industrial Development Mechanism for Agricultural Waste Recycling in Heilongjiang (No. QC2016099).

\section{REFERENCES}

[1] Lu, X., Xu, C.X. (2017). Dynamic efficiency and unconditional $\beta$ convergence of water resources utilization on the Yangtze river economic belt: based on three-stage dea-malmquist index method. Resources and Environment in the Yangtze Basin, 26(9): 1351-1358.

[2] Li, S.X., Cheng, S.X., Wu, Q.S. (2008). Regional difference of the efficiency of water usage in China. China Population Resources and Environment, 18(3): 54-65. https://doi.org/10.3969/j.issn.10022104.2008.03.041

[3] Li, M., Guo, P., Singh, V.P. (2016). An efficient irrigation water allocation model under uncertainty. $\begin{array}{lll}\text { Agricultural } & \text { Systems, } & \text { 144: }\end{array}$ https://doi.org/10.1016/j.agsy.2016.02.003

[4] Hu, J.L., Wang, S.C., Yeh, F.Y. (2006). Total-factor water efficiency of regions in China. Resources Policy, 31(4):

217-230. https://doi.org/10.1016/j.resourpol.2007.02.001

[5] Andre, F.J., Herrero, I., Riesgo, L. (2010). A modified DEA model to estimate the importance of objectives with an application to agricultural economics. Omega, 38(5): 371-382. https://doi.org/10.1016/j.omega.2009.10.002

[6] Sun, C., Zhao, L., Zou, W., Zheng, D. (2014). Water resource utilization efficiency and spatial spillover effects in China. Journal of Geographical Sciences, 24(5): 771-788. https://doi.org/10.1007/s11442-014-1119-x

[7] Battese, G.E., Coelli, T.J. (1992). Frontier production functions, technical efficiency and panel data: with application to paddy farmers in India. Journal of Productivity Analysis, 3(1-2): 153-169. https://doi.org/10.1007/BF00158774

[8] Kaneko, S., Tanaka, K., Toyota, T., Managi, S. (2004).
Water efficiency of agricultural production in China: regional comparison from 1999 to 2002. International Journal of Agricultural Resources, Governance and Ecology, 3(3-4): 231-251. https://doi.org/10.1504/IJARGE.2004.006038

[9] Fang, Q.X., Ma, L., Green, T.R., Yu, Q., Wang, T.D., Ahuja, L.R. (2010). Water resources and water use efficiency in the North China Plain: Current status and agronomic management options. Agricultural Water Management, $\quad$ 97(8): 1102-1116. https://doi.org/10.1016/j.agwat.2010.01.008

[10] Onishi, A., Sato, Y., Morisugi, M., Watanabe, T., Fukushima, Y. (2009). Evaluation of regional difference of agricultural water use efficiency in China. Journal of Japan Society of Hydrology and Water Resources, 22(5): 356-371. https://doi.org/10.3178/jjshwr.22.356

[11] Gao, S., Luo, Y., Yang, T. (2019). Research on analysis and evaluation method of vulnerability of water resources system. In IOP Conference Series: Earth and Environmental Science, 233(4): 042026. https://doi.org/10.1088/1755-1315/233/4/042026

[12] Bouman, B.A.M. (2007). A conceptual framework for the improvement of crop water productivity at different spatial scales. Agricultural systems, 93(1-3): 43-60. https://doi.org/10.1016/j.agsy.2006.04.004

[13] Liu, Y., Song, Y. (2019). Evaluation and influencing factor analysis of agricultural water resource efficiency in China based on super-efficiency SBM model. China Rural Water and Hydropower 61(1): 102-107. https://doi.org/10.3969/j.issn.1007-2284.2019.01.020

[14] Varghese, S.K., Veettil, P.C., Speelman, S., Buysse, J., Van Huylenbroeck, G. (2013). Estimating the causal effect of water scarcity on the groundwater use efficiency of rice farming in South India. Ecological Economics, 86: 55-64. https://doi.org/10.1016/j.ecolecon.2012.10.005

[15] Nanere, M., Fraser, I., Quazi, A., D’Souza, C. (2007). Environmentally adjusted productivity measurement: An Australian case study. Journal of environmental management, 85(2): 350-362.

[16] Pan, D., Ying, R.Y. (2013). Agricultural eco-efficiency evaluation in China based on SBM model. Acta Ecologica Sinica, 33(12): 3837-3845. https://doi.org/10.5846/stxb201207080953

[17] Tone, K. (2001). A slacks-based measure of efficiency in data envelopment analysis. European journal of operational research, 130(3): 498-509. https://doi.org/10.1016/S0377-2217(99)00407-5

[18] Wang, G., Chen, J., Wu, F., Li, Z. (2015). An integrated analysis of agricultural water-use efficiency: A case study in the Heihe River Basin in Northwest China. Physics and Chemistry of the Earth, Parts A/B/C, 89: 39. https://doi.org/10.1016/j.pce.2015.10.009

[19] Tong, J.P., Ma, J.F., Wang, S., Qin, T., Wang, Q. (2015). Research on agricultural water use efficiency in Yangtze river basin based on super-efficiency DEA and Tobit model. Resources and Environment in the Yangtze Basin, 24(4): 603-608. https://doi.org/10.11870/cjlyzyyhj201504010

[20] Li, J., Xu, D.Y. (2018). Agricultural water utilization efficiency and its influencing factors in China: Based on MinDW model. Journal of Environmental Economics, 4(3): 56-74. https://doi.org/10.19511/j.cnki.jee.2018.03.005 